\title{
Influence of the Surfactant Tyloxapol on Mucociliary Clearance in Human Respiratory Cystic Fibrosis Cells
}

\author{
Eckhard Beubler $^{\mathrm{a}}$ Rainald Fischer $^{\mathrm{b}} \quad$ Gerald Untersteiner $^{\mathrm{c}}$ \\ Wolfgang Strohmaier ${ }^{d}$ \\ ${ }^{a}$ Department of Experimental and Clinical Pharmacology, Medical University Graz, Graz, Austria; ${ }^{\text {b } L u n g e n a ̈ r z t l i c h e ~}$ \\ Praxis, München-Pasing, BRD, and 'bene-Arzneimittel GmbH, München, BRD, München, Germany; ' SciPharm Sàrl, \\ Luxembourg, Luxembourg
}

\section{Key Words}

Mucociliary clearance $\cdot$ Cystic fibrosis - Tyloxapol .

Human epithelial cells

\begin{abstract}
Dehydration of the apical surface of cystic fibrosis (CF) airway epithelia leads to a greatly impaired mucociliary clearance function in CF patients. In an in vitro cell model of human airway epithelia taken from CF patients and cultivated for 60 days, mucociliary clearance was zero. Tyloxapol, a synthetic surfactant, is able to restore the mucociliary clearance of the CF epithelia. The velocity of mucociliary clearance, using polystyrene microbeads as markers, increased within the first minute of tyloxapol treatment from zero to $12 \mu \mathrm{m} / \mathrm{s}$ and reached a maximum of $22 \mu \mathrm{m} / \mathrm{s}$ after $120 \mathrm{~min}$. In conclusion, tyloxapol restores mucociliary clearance in a MucilAir ${ }^{\mathrm{TM}}-\mathrm{CF}$ model and may accordingly be efficient in CF patients to restore mucociliary clearance.

(C) 2016 The Author(s)

Published by S. Karger AG, Basel
\end{abstract}

\section{Introduction}

Mucociliary clearance is an important defence mechanism that protects deeper airways from inhaled particles like allergens, pathogens or other pollutants. The airway

\section{KARGER}

E-Mail karger@karger.com www.karger.com/pha

\section{(C) 2016 The Author(s) \\ Published by S. Karger AG, Basel 0031-7012/16/0982-0001\$39.50/0}

This article is licensed under the Creative Commons AttributionNonCommercial-NoDerivatives 4.0 International License (CC BYNC-ND) (http://www.karger.com/Services/OpenAccessLicense). Usage and distribution for commercial purposes as well as any distribution of modified material requires written permission. respiratory epithelium consists of hair-shaped structures called cilia, which are covered by a protective mucus layer, the periciliary liquid (PCL). Located on top of that is an airway surface liquid layer in which foreign particles and microorganisms get stuck $[1,2]$. In the tracheobronchial tree, mucus is always moved toward and through the larynx and then swallowed. PCL dehydration reduces mucociliary clearance, leading to airway obstruction [3]. Mucus hypersecretion with abnormal mucus consistency and reduced mucociliary clearance occurs in respiratory diseases like cystic fibrosis (CF), respiratory distress syndrome (RDS) of the newborn, chronic obstructive pulmonary disease, asthma and also in heavy smokers.

There are several categories of human disease models to study respiratory diseases and drug development: cell lines, primary cells, 3D cell models, cell co-cultures, explants and in silico models [4]. At present, the most popular models are cell lines, derived from human tissues, which are mentioned in this paper.

The influence of surfactants on depressed mucociliary clearance in different situations and with different methods has been demonstrated previously [5-8]. One model has used the sputum of $15 \mathrm{CF}$ patients [8]. CF is a genetic disorder that affects the lungs, pancreas, kidneys, liver and intestines. In the airways, the disease causes difficulties in breathing and coughing up mucus. CF is caused by mutations of the gene for the CF transmembrane conduc- 
Fig. 1. Effect of tyloxapol on mucociliary clearance on CF epithelia. The graph demonstrates the average velocities of polystyrene microbeads obtained from 27 movies recorded on 9 independent batches from 3 different CF patients. Mucociliary clearance of MucilAir ${ }^{\mathrm{TM}_{-}} \mathrm{CF}$ without any treatment was zero. The addition of tyloxapol solution within the first minute increased mucociliary clearance with an observed maximal effect after $120 \mathrm{~min}$. The effect lasted until $48 \mathrm{~h}$. Values are mean \pm SEM.

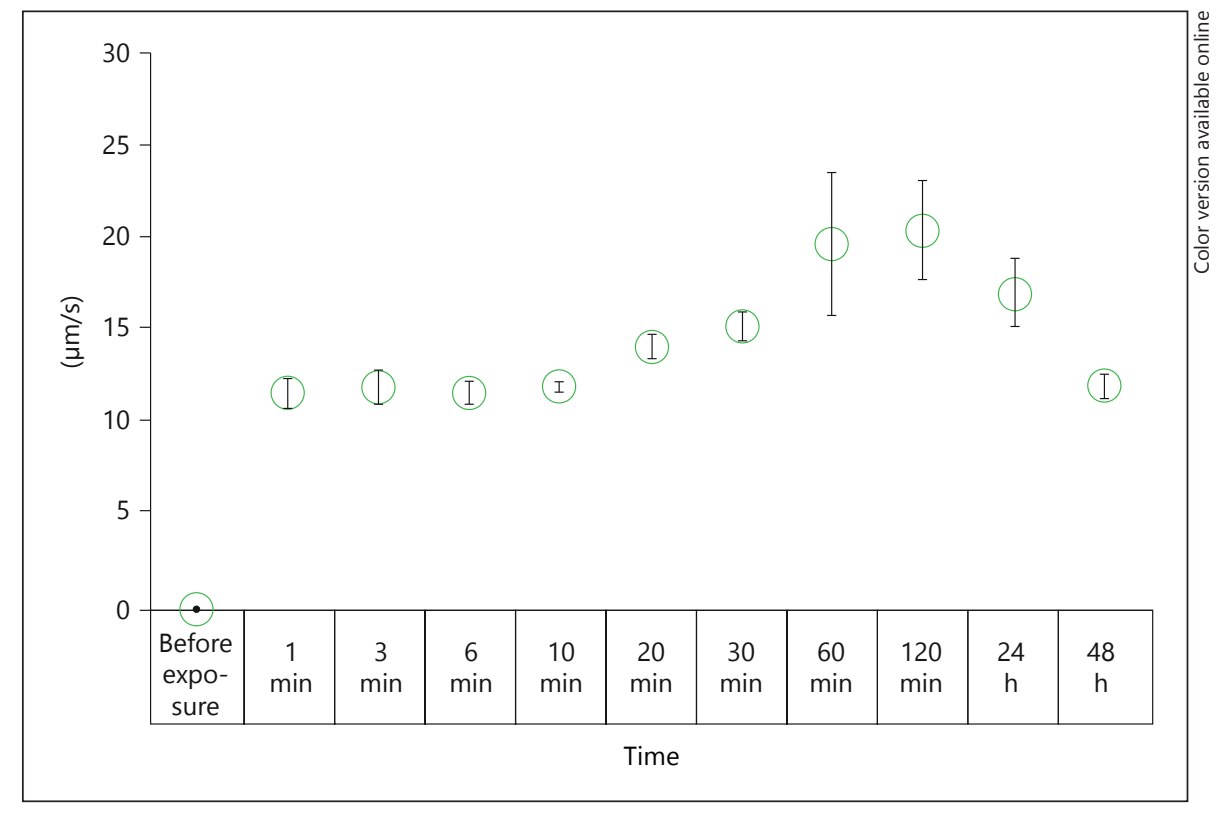

tance regulator (CFTR) protein. When CFTR is not functional, secretions that are normally thin become thick and in the airways, mucociliary clearance is disturbed.

In this paper, the effect of the surfactant tyloxapol on mucociliary clearance was studied in tissue batches taken from CF donors and cultivated for 60 days.

\section{Materials and Methods}

MucilAir ${ }^{\mathrm{TM}}$-CF (Epithelix Sàrl, Geneva, Switzerland) is a fully differentiated and ready-to-use 3D model of human airway epithelium, constituted with primary epithelial cells isolated from bronchial biopsies. It is commercially available and ready to use [4]. The cells used for this experiment were taken from 3 CF patients and cultivated for 60 days. Tissues originate from patients belonging to the homozygons $\rho$ F508 mutation, where $70 \%$ of CF-patients belong to [3]. In this study, the effect of tyloxapol on mucociliary clearance was evaluated on 3 independent batches from these $\mathrm{CF}$ patients of MucilAir ${ }^{\mathrm{TM}}$-CF (CF_MD0220; CF_MD0437; CF MD0485) and measurements of the movements of microbeads were performed in triplicates. The mucociliary clearance was monitored using a high-speed acquisition camera (Sony) connected to an Axiovert 200M microscope (Zeiss, Göttingen, BRD). Before exposure to tyloxapol, mucociliary clearance was quantified following the movement of plugs of mucus on the apical surface. Following the measurement of control clearance, $30 \mu \mathrm{l}$ of a saline solution of tyloxapol containing also $30 \mu \mathrm{m}$ polystyrene microbeads was applied on the apical surface of MucilAir ${ }^{\mathrm{TM}}$-CF. Then, $30 \mathrm{~s}$ movies showing the movement of the small beads were taken and analyzed using the imaging software Image Pro Plus (Mediacy, Media Cybernetics, Rockville, Md., USA). The first movies were acquired before the addition of the particles and then immediately after the addition of tyloxapol (1 min), then after 3, 6, 10, 20,30, 60, $120 \mathrm{~min}$,
24 and $48 \mathrm{~h}$. The movement of the beads was tracked and the velocity of each particle was calculated in order to determine the mean speed of the particles as a measurement of mucociliary clearance. The tyloxapol solution was obtained from a 1:2,000 dilution of Tacholiquin ${ }^{\circledR} 1 \%$ Lösung, which contained $10 \mathrm{mg}$ tyloxapol, $50 \mathrm{mg}$ glycerol and $20 \mathrm{mg}$ sodium bicarbonate. The final amount of tyloxapol in the $30 \mu \mathrm{l}$ administered was $150 \mathrm{ng}$. Polystyrene microbeads are from Sigma-Aldrich Chemie GmbH, Buchs, Switzerland.

\section{Results}

Mucociliary clearance was monitored on 3 independent batches from 3 different CF patients. All batches were covered by sticky mucus before the addition of vehicle or test solutions, and the mucociliary clearance of MucilAir ${ }^{\mathrm{TM}}$-CF was zero (fig. 1, before exposure). The stimulatory effect of tyloxapol was observed already during the first minute (fig. 1, $1 \mathrm{~min}$ ) and increased with a maximal observed effect at $120 \mathrm{~min}, 24 \mathrm{~h}$ and even $48 \mathrm{~h}$ after administration the effect was still observable.

\section{Discussion}

Due to the dehydration of the apical membrane of the CF airway epithelia [9-11], mucociliary clearance function is greatly impaired in CF patients. In this paper, an in vitro model of human airway epithelia, derived from $\mathrm{CF}$ patients and cultivated for 60 days, was used. According to the impaired mucociliary clearance function in CF-pa- 
tients, mucociliary clearance in these MucilAir ${ }^{\mathrm{TM}}-\mathrm{CF}$ is zero. Surfactants are used for many years to restore mucociliary clearance in models of impairment of the respiratory tract in neonatal RDS [6], CF [8], the anaesthetized dog [7] and in a porcine-gastric-mucin-model [12]. In the present experiments, tyloxapol, a synthetic nonionic surfactant is able to restore mucociliary clearance of the $\mathrm{CF}$ epithelia. Immediately after the addition of tyloxapol, the mucus is transported because of increased fluidity and mucociliary clearance is restored. The lowest velocity measured of the mucociliary clearance after the addition of tyloxapol was $12 \mu \mathrm{m} / \mathrm{s}$ and the maximum velocity was about $22 \mu \mathrm{m} / \mathrm{s}$. The result is consistent with the observation that tyloxapol reduced the viscosity of CF-sputum from $463 \pm 133$ to $128 \pm 52$ centipoise [13]. In conclusion, the surfactant tyloxapol is able to restore mucocilial clearance in the MucilAir ${ }^{\mathrm{TM}}-\mathrm{CF}$ model for at least $48 \mathrm{~h}$, with a maximal observed effect after $120 \mathrm{~min}$.

\section{Disclosure Statement}

G.U. is an employee of bene Arzneimittel GmbH; E.B., R.F. and W.S. declare no conflict of interest.

\section{References}

1 Mall MA: Role of cilia, mucus, and airway surface liquid in mucociliary dysfunction: lessons from mouse models. J Aerosol Med Pulm Drug Deliv 2008;21:13-24.

2 Antunes MB, Cohen NA: Mucociliary clearance - a critical upper airway host defense mechanism and methods of assessment. Curr Opin Allergy Clin Immunol 2007;7:5-10.

3 Tildy BE, Rogers DF: Therapeutic options for hydrating airway mucus in cystic fibrosis. Pharmacology 2015;95:117-132.

4 Huang S, Wiszniewski L, Constant S: The use of in vitro $3 \mathrm{D}$ cell models in drug development for respiratory diseases; in Kapetanovic I (ed): Drug Discovery and Development Present and Future, 2011.

5 Schürch S, Gehr P, Im Hof V, Geiser M, Green F: Surfactant displaces particles toward the epithelium in airways and alveoli. Respir Physiol 1990;80:17-32.
6 Rubin BK, Ramirez O, King M: Mucus rheology and transport in neonatal respiratory distress syndrome and the effect of surfactant therapy. Chest 1992;101:1080-1085.

7 De Sanctis GT, Tomkiewicz RP, Rubin BK, Schürch S, King M: Exogenous surfactant enhances mucociliary clearance in the anaesthetized dog. Eur Respir J 1994; 7:1616-1621.

8 Rubin BK: Therapeutic aerosols and airway secretions. J Aerosol Med 1996;9:123-130.

9 Donaldson SH, Boucher RC: Sodium channels and cystic fibrosis. Chest 2007;132:16311636 .

10 Letz B, Korbmacher C: cAMP stimulates CFTR-like $\mathrm{Cl}-$ channels and inhibits amiloride-sensitive $\mathrm{Na}+$ channels in mouse CCD cells. Am J Physiol 1997;272(2 pt 1): C657-C666.
11 Stutts MJ, Canessa CM, Olsen JC, Hamrick M, Cohn JA, Rossier BC, Boucher RC: CFTR as a cAMP-dependent regulator of sodium channels. Science 1995;269:847-850.

12 Khanal A, Sharma R, Corcoran TE, Garoff S, Przybycien TM, Tilton RD: Surfactant driven post-deposition spreading of aerosols on complex aqueous subphases. 1: high deposition flux representative of aerosol delivery to large airways. J Aerosol Med Pulm Drug Deliv 2015;28:382-393.

13 Ghio AJ, Marshall BC, Diaz JL, Hasegawa T, Samuelson W, Povia D, Kennedy TP, Piantodosi CA: Tyloxapol inhibits NF-kappa B and cytokine release, scavenges HOCI, and reduces viscosity of cystic fibrosis sputum. Am J Respir Crit Care Med 1996;154(3 pt 1):783788 